\title{
Comparing the Efficacy of Intra-dermal Platelet Rich Plasma (PRP) Versus 50\% Trichloracetic Acid (TCA) using Cross Technique for Atrophic Acne Scars
}

Maryam Mumtaz, Tahir Hassan, Muhammad Khurram Shahzad, Nazia Hanif, Sarah Anwar and Rubab Anjum

Department of Dermatology, Sheikh Zaid Hospital, Rahim Yar Khan, Pakistan

\begin{abstract}
Objective: To compare the efficacy of intra-dermal platelet rich plasma (PRP) versus $50 \%$ trichloracetic acid (TCA) using chemical reconstruction of skin scars (CROSS) technique in the treatment of atrophic acne scars.

Study Design: Non-randomised controlled trial.

Place and Duration of Study: Sheikh Zayed Hospital, Rahim Yar Khan, from October 2019 to April 2020.

Methodology: In this study, cases of either gender and age 20 to 40 years with atrophic acne scars were included. The severity of the scar was graded on the basis of global acne scarring grading system. The cases in group A were managed by monthly injections of $1 \mathrm{ml}$ intra-dermal PRP every month; while those in Group B were given treatment with 50\% TCA, which was applied by CROSS technique every month. Both treatments were offered for three months. They were assessed at every four weeks for initial three months. Then these cases were followed another three months and final outcome was seen at $6^{\text {th }}$ month.

Results: In this study, there were 92 cases, 46 in each group. The mean age in group A and B was $27.72 \pm 8.05$ vs. $26.50 \pm$ 8.20 years $(p=0.474)$. The mean global scar score at baseline was $36.07 \pm 5.37 \mathrm{vs} .38 .70 \pm 4.80(p=0.015)$. The mean scar score at 4 weeks was $28.87 \pm 5.27$ vs. $29.00 \pm 3.07$ ( $p=0.885$ ), at 8 weeks $23.22 \pm 4.10$ vs. $23.11 \pm 2.49(p=0.878)$, at 12 weeks $14.15 \pm 3.05$ vs. $17.57 \pm 4.51(p<0.001)$, and at 24 weeks it was $7.09 \pm 1.46$ vs. $10.09 \pm 3.58(p=<0.001)$.

Conclusion: PRP is significantly better than $50 \%$ TCA in reducing post-acne atrophic scars.
\end{abstract}

Key Words: Acne, Atrophic scar, Platelet rich plasma, 50\% TCA.

How to cite this article: Mumtaz M, Hassan T, Shahzad MK, Hanif N, Anwar S, Anjum R. Comparing the Efficacy of Intra-dermal Platelet Rich Plasma (PRP) Versus 50\% Trichloracetic Acid (TCA) using Cross Technique for Atrophic Acne Scars. J Coll Physicians Surg Pak 2021; 31(01):55-59.

\section{INTRODUCTION}

Acne is one of the highly concerning entity encountered in adolescent population and post-acne scarring adds more to overall morbidity in terms of cosmetic disfigurement, and social and psychological stress. Its distribution is variable and it is more prevalent in young age, especially in females. The most common areas of involvement are those with rich distribution of pilosebaceous glands. The prevalence in general population is around $1 \%$. ${ }^{1,2}$

Acne scars are broadly subdivided into three major categories: atrophic, hypertrophic, and keloids: where atrophic scars are the highest in number. Atrophic scars are furtherclassified into ice pick, rolling, and boxcars.

Correspondence to: Dr. Maryam Mumtaz, Department of Dermatology, Sheikh Zaid Hospital, Rahim Yar Khan, Pakistan

E-mail: maryammumtaz@hotmail.com

Received: September 14, 2020; Revised: December 19, 2020; Accepted: December 30, 2020

DOI: https://doi.org/10.29271/jcpsp.2021.01.55
The underlying pathophysiology is multifactorial and largely relies upon chronic inflammation and scarring at the site of subcutaneous matrix. The major steps in scarring include inflammation, granulation formation and matrix remodelling. They are usually asymptomatic and might have some itching or other symptoms, if associated with super-added infection. ${ }^{3,4}$ The diagnosis is made clinically; and severity is further graded on the basis of various tools and scores. Tissue biopsy and histopathology is seldom needed, which guides towards particular subtype. The most commonly practised scales are Vancouver scarscale (VSS), Good MAN and Baron grading scale, patient and observerscarscale etc. ${ }^{5,6}$

Early diagnosis and prompt treatment is the key to success. The treatment options are broadly divided into energy-based and non-energy-based, where former comprises lasers (both ablative and non-ablative), fractional, radiofrequency lasers; and latter contains derm abrasions, micro needling, fillers, peels and drugs. Each carries different degree of success and side effect profile. ${ }^{7,8}$

Platelet rich plasma is a relatively newer entity; while, trichloracetic acid was used conventionally over years in different strengths ranging from $35 \%$ to $100 \%$ in various application 
methods; and had shown promising results but side effect profile was the concern, which led to the search of newer therapies like PRP., ${ }^{9,10}$ The studies were also done on a particular group of scar and with smaller sample size of 25 to 30 .

That is why this study was planned to compare newer PRP with conventional TCA, especially with a strength of $50 \%$ (for which data is scarce) in all types of atrophic acne scars to find the betteragent.

\section{METHODOLOGY}

The approval of this study was taken from Ethical Review Committee via reference number $02 / \mathrm{IRB} / \mathrm{SZMC} / \mathrm{SZH}$. This was a non-randomised controlled trial, that was carried out from October 2019 to April 2020 at Sheikh Zayed Hospital, Rahim Yar Yar Khan. Cases of either gender with age 20 to 40 years suffering from atrophic type of acne scar lasting for less than one year and no active acne were included for which diagnosis was made clinically with history of acne vulgaris and scarring at the facial area. Exclusion criteria consisted of patients with scar duration more than one year, any bleeding disorder, presence of active acne on face, active infection (purulent discharge from the site), keloid tendency, pregnancy and lactating women. An informed written consent was taken from each subject to include in this study; and were also explained the procedures and side effect profiles of the drugs used in the study.

The sample size was calculated as 92 (46 in each group) by keeping the confidence level equal to $95 \%$, power equal to $80 \%$, and the very good response as $46.7 \%$ with PRP and $20 \%$ with $100 \%$ TCA as there was no one-to-one comparison with $50 \%$ TCA before. ${ }^{11}$ Total 134 cases were analysed, 92 were finalised, which were divided into two groups. There was no lost-to-follow-up. Final data was analysed on these 46 cases of each group.

Then these cases were subdivided into two equal groups by simple lottery method. Thorough history was taken of each patient, including demographic history, disease history, age of onset, duration of disease and treatment history. Dermatological examination was performed and grading of acne scars was done according to Goodman and Baron global acne scarring grading system (Tablel). Then mean scoreatbaselinewas calculated.

Patients were explained in detail about the procedure. Of cases in group A, complete blood count, including baseline platelet count, was performed. Area of interest in both the groups was wiped with spirit before procedure.

In group A, after cleaning the face with spirit, it was anesthetised using a topical anesthetic cream Anestin (10.56\% lidocaine) for about 45 minutes. Autologous whole blood of $20 \mathrm{~mL}$ was collected and pure platelet rich plasma was prepared, using a special sterile vacutainer tube containing an anticoagulant. PRP was obtained manually by two-step procedure, using a centrifuge machine. First spin was performed at 1500 revolu- tions per minute (RPM) for 10 minutes. Second spin was performed at a rate of 4000 RPM for 10 minutes. Thus obtaining a two-part plasma. Upper two-thirds was platelet poor plasma (PPP) and was discarded. Lower $1 / 3^{\text {rd }}$ was platelet rich plasma (PRP).

Just before injection, $0.1 \mathrm{ml}$ of calcium chloride was added for each $1 \mathrm{ml}$ of PRP to activate the platelets. PRP was injected intra-dermally through a 30G needle (insulin syringe) deep to each scar on both cheeks. The amount injected was sufficient to elevate the scar and the end point was taken as the elevation of scar. Total amount injected was 3-4 $\mathrm{mL}$ depending on the number of scars. After injecting, the site was gently massaged and compressed for a few seconds to control the bleeding. Patients were given topical sunscreens. All the patients were assessed for side effects like pain, edema, erythema, hyperpigmentation and development of active acne lesions during the treatment.

In patients with group B, after cleaning the face with spirit, local anesthetic was not used and patients were comfortable during the procedure. The skin was stretched to reach the bottom of scar and 50\% TCA was then focally applied on entire depth of atrophic acne scar using a tooth pick; 50\% TCA was selected as higher concentrations had more side effect profile. Care was taken to avoid spillage to the surrounding skin. The skin was monitored carefully until a frosted appearance was seen. Frosting was generally seen in 10-15 seconds and was a result of coagulation of epidermal and dermal proteins. Patients were instructed to wash their face with water immediately after 7-10 minutes. Sunscreen was applied after the procedure.

Both treatments were offered for only three months. They were assessed at every four weeks for initial three months. Then these cases were followed another three months and final outcome was seen at six month, which was assessed on the basis of global acne scarring grading system, and mean score was calculated.

SPSS version 24 was used for data analysis. Qualitative data, like gender, was presented as frequency and percentages; while quantitative data like age, BMI, duration of scar and global acne score were presented as mean \pm S.D. Chi-square and independent samplet-tests were used for categorical and numerical data stratification, respectively; and $p<0.05$ was taken as significant.

\section{RESULTS}

In this study, there were 92 cases, 46 in each group. The mean age in group $A$ and $B$ was $27.72 \pm 8.05$ vs. $26.50 \pm 8.20$ years $(p=0.474)$. Table II further reveals BMI, duration of scar and gender distribution in both groups. The mean global scar score at baseline was $36.07 \pm 5.37$ vs. $38.70 \pm 4.80$ with $p=0.015$. There was no significant difference in mean scar score at four weeks $(p=0.885)$, at eight weeks $(p=0.878)$, while there was significant difference at 12 weeks $(p<0.001)$ and at 24 weeks with $p$-value of $<0.001$, as displayed in Table III. 
Table I: Goodman and Baron's quantitative scar scale.

\begin{tabular}{|l|c|c|}
\hline \multirow{2}{*}{ Grade (type) } & \multicolumn{2}{|c|}{ No. of lesions } \\
\cline { 2 - 3 } & $\mathbf{1 - 1 0}$ & $\mathbf{1 1 - 2 0}$ \\
\hline A. Milder scarring - macular erythematous, pigmented, mildy atrophic dish-like. & & \\
\hline $\begin{array}{l}\text { B. Moderate scarring - moderately atrophic dish like, punched out small } \\
\text { scars with, shallow bases but atrophic areas (<5 mm). }\end{array}$ & 2 pts & 4 pts \\
\hline $\begin{array}{l}\text { C. Severe scarring - punched out with deep but normal bases, punched out } \\
\text { with deep abnormal bases, linear or trpughed dermal scarring, deep and } \\
\text { broad atrophic areas. }\end{array}$ & 3 pts & 6 pts \\
\hline D. Hyperplastic papular scars. & 2 pts & 4 pts \\
\hline $\begin{array}{l}\text { E. Hyperplastic keloidal or hypertrophic scars. } \\
\text { Area }<5 \mathrm{~cm}^{2}-6 \text { pts }\end{array}$ & Area $5-20 \mathrm{~cm}^{2}-12 \mathrm{pts}$ & $\begin{array}{c}\text { Area }>20 \mathrm{~cm}^{2}-18 \\
\text { pts }\end{array}$ \\
\hline
\end{tabular}

Table II: Demographics of study subjects ( $n=46$ each).

\begin{tabular}{|l|c|c|}
\hline Study variables & Group A & Group B \\
\hline Age (years) & $27.72 \pm 8.05$ & $26.50 \pm 8.20$ \\
\hline BMI $\left(\mathrm{kg} / \mathrm{m}^{2}\right)$ & $24.83 \pm 3.83$ & $24.41 \pm 2.61$ \\
\hline Duration of scar (months) & $6.37 \pm 1.44$ & 0.474 \\
\hline Gender & $27(58.7 \%)$ & 0.547 \\
Male & $19(41.3)$ & $22(47.8)$ \\
Female & & 0.008 \\
\hline
\end{tabular}

Table III: Comparison of mean acne score ( $n=46$ in each group).

\begin{tabular}{|l|c|c|c|}
\hline Global acne score & Group A & Group B & p-value \\
\hline Pre-treatment & $36.07 \pm 5.37$ & $38.70 \pm 4.80$ & 0.015 \\
\hline 4 weeks & $28.87 \pm 5.27$ & $29.00 \pm 3.07$ & 0.885 \\
\hline 8 weeks & $23.22 \pm 4.10$ & $23.11 \pm 2.49$ & 0.878 \\
\hline 12 weeks & $14.15 \pm 3.05$ & $17.57 \pm 4.51$ & $<0.001$ \\
\hline 24 weeks & $7.09 \pm 1.46$ & $10.09 \pm 3.58$ & $<0.001$ \\
\hline
\end{tabular}

\section{DISCUSSION}

Post-acne scarring is a well known entity and is the most common subtype. Considering its asymptomatic nature, globally the most common reason to acquire therapies is cosmetic disfigurement. There are different treatment modalities, but are time-consuming as well as variable in efficacies. Longer duration of treatment and slow response to the therapy are the two major concerns for losing the patients on long term follow-up..$^{12,13}$

In the present study, intra-dermal PRP was significantly better at 12 and 24 weeks as compared to 50\% TCA applied by CROSS technique, and it was seen that mean scar score at 12 weeks was $14.15 \pm 3.05$ vs. $17.57 \pm 4.51$ ( $p<0.001)$; and at 24 weeks it was $7.09 \pm 1.46$ vs. $10.09 \pm 3.58$ with $p$ value of $<0.001$. There was lack of data regarding one-to-one comparison of these two agents, and especially in this (50\%) strength as TCA has been used in various strengths and combination, especially $70 \%$ and $100 \%$ with or without combination of other agents. ${ }^{9,11}$

According to a study done by Nofal et al., they compared PRP with $100 \%$ of TCA applied by same CROSS technique, and it was seen that PRP was better than TCA just like the findings of the present study. They further found that, in grade I of acne scar, there were no cases, in grade 2 efficacy of PRP vs. $100 \%$ TCA was $40 \%$ vs. $33 \%$ in grade $3,33 \%$ vs. $40 \%$, and in grade 4 , it was $26.7 \%$ each. ${ }^{11}$
Apart from one-to-one comparison, for which very little data was available, they also compared these modalities individually with other therapeutic agents as well. In another study done by Porwal et al., they compared PRP combined with derma roller vs. derma roller alone and treatment assessment was done by Goodman and Baron's quantitative scores. It was found that a statistically significant difference was noted between the two groups after the treatment $(p<0.05)$, favouring PRP and derma roller group. They further described that improvement was noted in $58.58 \%$ cases in PRP and derma roller combined and in $43.03 \%$ in derma roller alone; and on quantitative assessment, the mean acne score after third session was $18.58 \pm 4.12$ in PRP and derma roller combined as compared to $23.58 \pm 5.71$ in derma roller alone group. ${ }^{14}$

Aamir et al., on other hand, assessed the utility of 35\% TCA on the basis of laid down criteria with CROSS technique in their nine cases, out of which seven were females. They found that five $(55.5 \%)$ out of nine patients experienced good clinical response, while four patients had excellent, i.e. more than $70 \%$ improvement. Only one patient rated the results to be $>25 \%$ (fair) despite the clinical improvement being more than $50 \%{ }^{15}$

In another study done by Kaur et al., where they analysed multiple outcomes in cases managed wit 50\% TCA by using in CROSS technique. They revealed that in all the patients, scar grading improved from grade 4 to grade 2 and results 
were graded excellent, good, and fair in 6, 3, and 1 patients respectively. ${ }^{16}$

According to another systemic review analysis done by Kravvas et al., they described that all of their cases managed with micro-needling achieved some improvement in scar appearance in the range of $31-62 \%$. Dermal fillers also led to favourable outcomes. In particular, treatment with PPMA led to improvement in $84 \%$ of patients. Utilising chemical peels, trichloroacetic acid (TCA) CROSS achieved $>70 \%$ improvement in $73.3 \%$ of patients, whereas $20 \%$ glycolic acid did not lead to any improvement in $25 \% .{ }^{17}$

Ramadan et al. performed a split-face study on 20 patients only with rolling acne scars, comparing the effects of subcision with those of $100 \%$ TCA CROSS chemical peel. They found a mean decrease in the size of scars following subcision and peeling by $0.3867 \pm 0.09 \mathrm{~cm}^{2}$ and $0.08657 \pm 0.090$ $\mathrm{cm}^{2}(p<0.01) .{ }^{18}$ In a study done by Narayanan et al., the combination of subcision, 50\% TCA with CROSS technique was used as in the present study was and the pre- and posttreatment outcome was assessed in the form of photographic record; and it was observed that out of 14 patients with grade 4 acne scars, $9(64.3 \%)$ patients improved to grade 2 , and 5 (35.7\%) patients improved to Grade 3. Out of 10 patients with Grade 3 scars, 6 (60\%) patients improved to grade 1 , and $4(40 \%)$ patients were improved to grade 2 at the end of the study. All five patients with Grade 2 scars showed significant improvement from baseline. ${ }^{19}$

Interestingly, in this study more males were seen with acne scaring as compared to females; though in adulthood it is more common in females. The reason for this could not be found. This study was limited to only three months. Treatment could have been extended beyond three months in both good or slow responders to attain further efficacy. No side effect profile data was collected in the scope of this study.

\section{CONCLUSION}

Platelet rich plasma (PRP) is recently proving its role in various modalities and is found significantly better than $50 \%$ TCA in reducing post-acne atrophic scars. Future studies can help in assessing its long term benefits and can also look for side effect profiles.

\section{CONFLICT OF INTEREST:}

The authors declared no conflict of interest.

ETHICAL APPROVAL: Ethical approval was taken from Institutional Review Board Sheikh Zayed Hospital, Rahim Yar Khan prior to the initiation of the study.

\section{PATIENTS' CONSENT:}

Informed consents were obtained from patients to publish the data concerning this case.

\section{AUTHORS' CONTRIBUTION:}

MM: Literature review, article writing, design, conception, data collection, analysis.

TH, MKS: Conception, design, analysis.

$\mathrm{NH}$ : Study design.

SA, RA: Conception.

\section{REFERENCES}

1. Tan J, Kang S, Leyden J. Prevalence and risk factors of acne scarring among patients consulting dermatologists in the USA. J Drugs Dermatol 2017; 16(2):97-102.

2. Rajar UDM, Majeed R, Sheikh F, Sheikh I, Siddique AK, Kumar S. Scarring in acne patients - a study done at Isra University Hyderabad. J Pak Med Assoc 2009; 59(8): 525-27.

3. Wolkenstein P, Machovcová A, Szepietowski JC, Tennstedt $D$, Veraldi S, Delarue A. Acne prevalence and associations with lifestyle: a cross-sectional online survey of adolescents/young adults in 7 European countries. J Eur Acad Dermatol Venereol 2018; 32(2):298. doi: 10.1111/ jdv.14475.

4. O'Neill AM, Gallo RL. Host-microbiome interactions and recent progress into understanding the biology of acne vulgaris. Microbiome 2018; 6:177.

5. Goodman GJ, Baron JA. Postacne scarring - a quantitative global scarring grading system. J Cosmet Dermatol 2006; 6(1):1473. doi: 10.1186/s40168-018-0558-5.

6. Finlay AY, Torres V, Kang S, Bettoli V, Dreno B, Goh CL, et al. Classification of acne scars is difficult even for acne experts. J Eur Acad Dermatol Venereol 2013; 27(3): 391-3. doi: 10.1111/j.1468-3083.2012.04461.x.

7. Saluja SS, Walker ML, Summers EM, Tristani-Firouzi $P$, Smart DR. Safety of non-ablative fractional laser for acne scars within 1 month after treatment with oral isotretinoin: A randomized split-face controlled trial. Lasers Surg Med 2017; 49(10):886-90. doi: 10.1002/ Ism.22711.

8. Min S, Park SY, Yoon JY, Suh DH. Comparison of fractional microneedling radiofrequency and bipolar radiofrequency on acne and acne scar and investigation of mechanism: comparative randomized controlled clinical trial. Arch Dermatol Res 2015; 307(10):897-904. doi: 10.1007/ s00403-015-1601-z.

9. Agarwal N, Gupta LK, Khare AK, Kuldeep CM, Mittal A. Therapeutic response of $70 \%$ trichloroacetic acid cross in atrophic acne scars. Dermatol Surg 2015; 41(5):597-604. doi: 10.1097/DSS.0000000000000355.

10. Fabbrocini G, De Vita V, Pastore F, Panariello L, Fardella N, Sepulveres $R$, et al. Combined use of skin needling and platelet-rich plasma in acne scarring treatment. Cosmet Dermatol 2011; 24:177-83.

11. Nofal E, Helmy A, Nofal A, Alakad R, Nasr M. Platelet-rich plasma versus CROSS technique with $100 \%$ trichloroacetic acid versus combined skin needling and platelet rich plasma in the treatment of atrophic acne scars: a comparative study. Dermatol Surg 2014; 40(1):64-73. doi: $10.1111 /$ dsu. 0000000000000091 . 
12. Connolly D, Vu HL, Mariwalla K, Saedi N. Acne scarring pathogenesis, evaluation, and treatment options. J Clin Aesthet Dermatol 2017; 10(9):12-23.

13. Hayashi N, Miyachi Y, Kawashima M. Prevalence of scars and "mini-scars", and their impact on quality of life in Japanese patients with acne. J Dermatol 2015; 42(7): 690-6. doi: 10.1111/1346-8138.12885.

14. Powal S, Chahar YS, Singh PK. A comparative study of combined dermaroller and platelet-rich plasma versus dermaroller alone in acne scars and assessment of quality of life before and after treatment. Ind J Dermatol 2018; 63(5):403-08. doi: 10.4103/ijd.IJD_118_17.

15. Aamir S, Mirza MAR, Iqbal Z. CROSS treatment of acne scars with trichloacetic acid. J Pak Assoc Dermatol 2013; 23(2):11-5.
16. Kaur J, Kalsy J. Subcision plus $50 \%$ trichloroacetic acid chemical reconstruction of skin scars in the management of atrophic acne scars: A cost-effective therapy. Indian Dermatol Online J 2014; 5(1):95-97. doi: 10.4103/22295178.126053.

17. Kravvas G, Al-Niami F. A systematic review of treatments for acne scarring. Part 1: Non-energy-based techniques. Scars Burn Healing 2017; 3:1-17. doi: 10.1177/ 2059513117695312.

18. Ramadan SA, El-Komy MM, Bassiouny DA, El-Tobashy SA. Subcision versus $100 \%$ trichloroacetic acid in the treatment of rolling acne scars. Dermatol Surg 2011; 37(5):626-33. doi: 10.1111/j.1524-4725.2011.01954.x.

19. Narayanan S, Nallu K, Venu S, Ganapathi AR. Combined treatment modalities in atrophic acne scars: A prospective study. Int J Res Dermatol 2019: 5(2):1-5. 